\title{
Developing Second Language Writing Through Scaffolding In The ZPD: A Magazine Project For An Authentic Audience
}

John W. Schwieter, Wilfrid Laurier University, Canada

\begin{abstract}
In the present study, Vygotsky's $(1978,1986)$ sociocultural framework of the zone of proximal development (ZPD) and scaffolding writing (Bodrova \& Leong, 1995, 1996; Ross, 1976) are used as the theoretical basis to study the development of second language writing. A course project is presented in which advanced English language learners of Spanish acted as authors and editors to create their own professional magazines for an authentic audience. In the project, each student authored four essays which went through four peer- and instructor-edited stages of scaffolding writing techniques. After each stage, ratings were given by the editors who also facilitated feedback debriefing sessions (Lidz, 1991). Statistical analyses revealed significant improvement within the four essays demonstrating writing development of subsequent revisions of a single essay. There was also significant improvement between the four essays revealing a linear, continuous writing development. In all, these results support a notion that scaffolding writing techniques and feedback debriefing sessions within the ZPD effectively develops writing skills in second language learning when contextualized through a writing workshop involving the creation of a professional magazine designed for an authentic audience.
\end{abstract}

Keywords: zone of proximal development, scaffolding, writing development, second language writing

\section{INTRODUCTION}

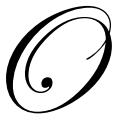

ne prominent framework in sociocultural theory applied to second language learning is Vygotsky's (1978, 1986, 1987) notion of the Zone of Proximal Development (ZPD). The basic idea behind this theory is that a more knowledgeable learner or expert facilitates the learning development of a novice learner within the appropriate zone of his/her aptitude. According to Vygotsky (1978), the ZPD is defined as "the distance between the actual developmental level as determined by independent problem solving and the level of potential development as determined through problem solving under adult guidance, or in collaboration with more capable peers" (p. 86). The notion underpinning the ZPD was originally put forth to argue against the use of standardized testing as a way to measure students' abilities. In fact, the idea of the ZPD fueled the hypothesis that it is more viable to estimate such skills through a conceptual framework which focuses on the differences between learners' abilities to problem solve independently through assisted learning (Berk \& Winsler, 1995; Brown \& Reeve, 1987; Wertsch, 1979, 1985; but see also Moll, 1990; Moll \& Whitmore, 1993; Newman, Griffin, \& Cole, 1989; Rogoff \& Wertsch, 1984 for similar interpretations of the ZPD; and van der Veer \& Valsiner, 1991 for an overview of Vygotsky's work).

A widely-acceptable term that is commonly linked to the theory of ZPD illustrating how guidance supports developmental learning through the ZPD is the notion of scaffolding (Adair-Hauck \& Donato, 1994; Aljaafreh \& Lantoff, 1994; Antón \& DiCamilla, 1998; Balaban, 1995; Bruner, 1978; Cazden, 1983; Daniels, 1994, 2001; de Guerrero \& Villamil, 2000; DiCamilla \& Antón, 1997; Donato, 1994; Lantoff \& Aljaafreh, 1995; Lidz, 1991; Ohta, 1995; Rommetveit, 1985; Stone, 1993, 1998, 2004; Stone \& Wertsch, 1984; van Lier, 1996; Wertsch \& Stone, 1985; 
Wood \& Middleton, 1975; Wood, Bruner, \& Ross, 1976). Lidz identifies scaffolding learning as "the mediator's adjusting the complexity and maturity of the teaching interaction to facilitate the [learner's] mastery of the task; providing support when necessary; and providing encouragement and prompts to the [learner] to move ahead when ready" (p. 80). Recently, Borthick, Jones, and Wakai (2003) suggested that scaffolding still has not yet been defined in a concrete manner and argued a need to define it more specifically. A number of researchers over the last decade or so have attempted to better identify what is known as scaffolding by explaining it through a variety of types of techniques including conceptual scaffolding (Bell \& Davis, 1996), soft and hard scaffolding (Holton \& Clarke, 2006; Saye \& Brush, 2002; Simons \& Klein, 2007), contingent scaffolding (van Lier, 1996), reciprocal scaffolding (Holton \& Clarke, 2006), mutual scaffolding (de Guerrero \& Villamil, 2000; Donato, 1994), technical scaffolding (Yelland \& Masters, 2007), and hybrid learning scaffolding (Santoso, 2008). The present study will follow the general theoretical contributions of Lidz and Bodrova and Leong $(1995,1998)$ to interpret and implement scaffolding writing.

The present study investigates the extent to which scaffolding writing techniques within second language learners' ZPDs facilitate second language writing development. Advanced English language learners of Spanish participated in a semester-long course project by creating a professional magazine intended for an authentic audience. The magazine consisted of descriptive, narrative, expository, and persuasive stylistic essays composed by the students and edited and rated by their peers and instructor. Each essay went through four stages of scaffolding writing techniques and feedback debriefing sessions. In the upcoming sections, the ZPD and scaffolding writing are described in more detail followed by a description of the present study. In this description, the magazine project and its objectives in the development of second language writing skills is introduced. Finally, the results from the statistical analyses are discussed and theoretical implications for future studies and pedagogical considerations for the second language classroom are presented.

\section{THEORETICAL BACKGROUND}

\section{Zone of Proximal Development}

The ZPD is a theoretical concept that is shaped by a sociocultural theory in which learning is interpreted as an intricate, social act facilitated within a specific cultural environment. This environment specifies that learning is best developed when a novice learner is assisted by another learner who has special training and/or advanced skills in the theme in question. De Guerrero and Villamil (2000) argue that in order for intellectual growth to occur, a certain degree of social interaction and collaboration must occur between the novice and expert learner and must take place within the novice learners' ZPD. This interaction is facilitated via scaffolding mediated assistance in which language is the main tool of mediation (de Guerrero \& Villamil, 1994, 2000). As a pedagogical consideration in the second language writing classroom, an excellent way to achieve this context is through peer-editing followed by feedback debriefing sessions focusing on ways to improve writing. This collaboration session would be critical in guiding the novice student through stages of his/her ZPD. If employed as a regular part of the teaching methodology, the feedback sessions have the potential for long-term writing development as students build upon what they have learned in prior sessions to enhance subsequent tasks.

The theoretical explanation for the debriefing session example described above can be seen in Figure 1 in which learning development occurs over time within several ZPDs. The figure depicts separate stages of learningeach consisting of assisted scaffolding techniques that lift learners from their individual performance level to a level in which, at one point they could only perform with assistance. For example, if a novice learner can only write isolated, elementary-level sentences by him/herself, assisted learning (i.e., instruction at a slightly higher level of the novice learner) through scaffolding exercises (e.g., editing, textual reconstruction, and feedback debriefing sessions) will allow him/her to subsequently perform at that same level without assistance. Thus, one ZPD's level of assisted learning is the next ZPD's level of unassisted learning. Indeed, Vygotsky (1987) argues that:

Instruction is only useful when it moves ahead of development. When it does, it impels or wakens a whole series of functions that are in a stage of maturation lying in the ZPD. This is the major role of instruction in development...instruction would be completely unnecessary if it merely utilized what had already matured in the developmental process, if it were not itself a source of development (p. 212). 


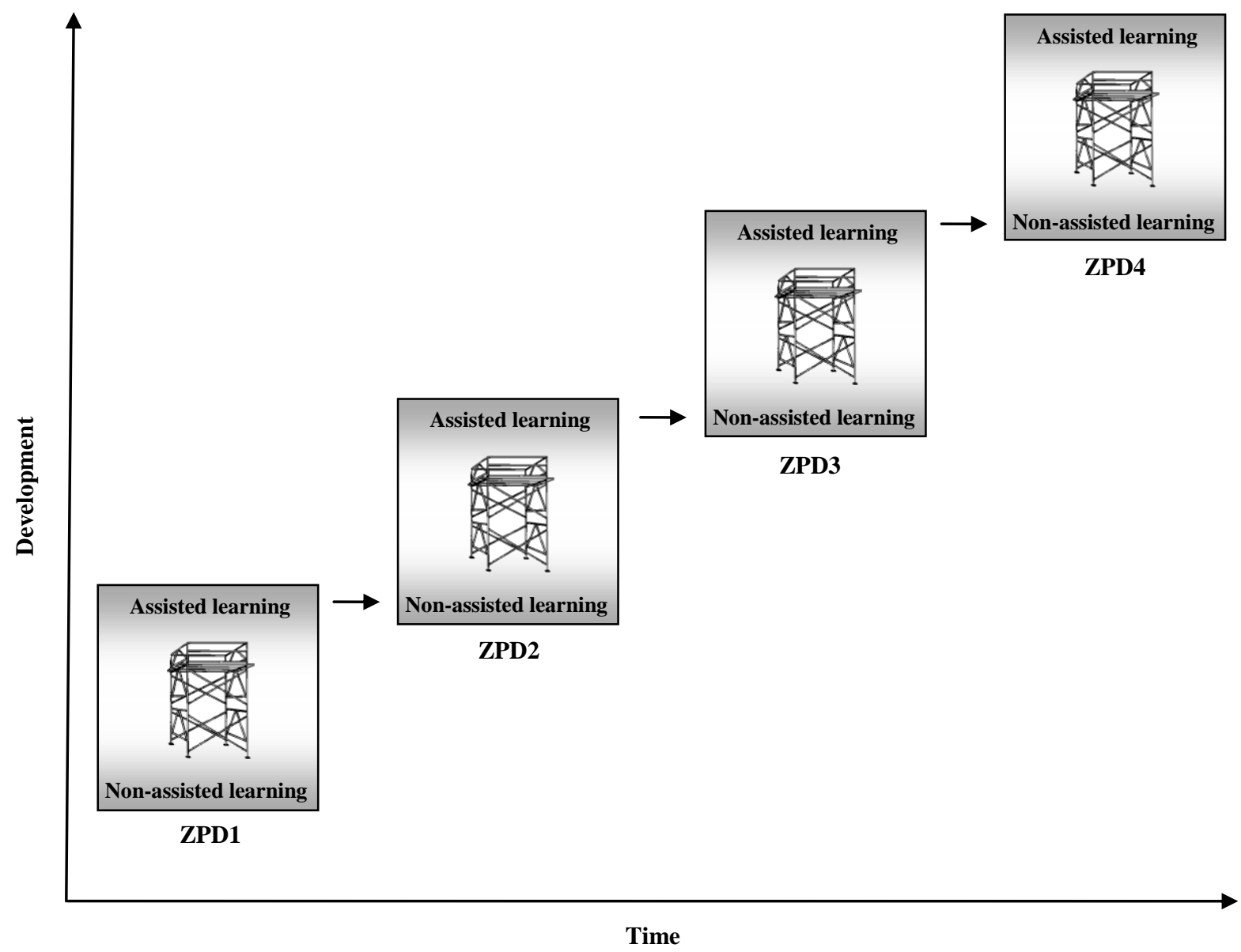

Figure 1. Developmental progression in a language learner's ZPD through scaffolding.

\section{Scaffolding writing within the ZPD}

Although a variety of pedagogical approaches to writing development have been applied in the second language classroom (see Reichelt, 2001; Silva \& Brice, 2004; Verenikina, 2003 for reviews), the present study will pay particular attention to scaffolding writing techniques. Most simply put, scaffolding writing techniques make up the process in which experts help novice learners to develop a higher level of writing skills. Wood et al. (1976) hypothesize that successful scaffolding techniques consist of the following six actions: 1) maintaining the novice learner's attention; 2) reducing variability within the task; 3) realizing goals within the task; 4) highlighting critical learning characteristics; 5) minimizing frustration during learning development; 6) providing solutions to problems. These researchers further argue the importance of the expert's familiarity with these criteria and specify that learning development is less effective when the expert is not familiar with the theory of how the task is solved or how the novice is hypothesized or expected to solve that task (see also de Guerrero \& Villamil, 2000). Lidz (1991) more recently provided an extension to Wood et al.'s criteria by characterizing the most important elements of scaffolding (see Table 1). 
Table 1

Lidz's components of assisted learning via scaffolding

1. Influence the learner's actions through interaction, engagement of attention, and goals.

2. Highlight important aspects, mark relevant differences, and elaborate detailed information.

3. Draw on the learner's past experiences and potential future ones.

4. Visualize the learner's work through his/her eyes.

5. Share experiences that may stimulate new ideas.

6. Manipulating the task to facilitate problem solving and induce strategic thinking.

7. Encourage the learner that he/she has done something good to boost self-esteem.

8. Challenge the learner within but not beyond his/her ZPD.

9. Remember that the learning experience is the learners not the experts to avoid competition.

10. Be familiar with the learner's behavior and respond to it appropriately.

11. Give the learner a sense of caring and enjoyment in the task.

12. Find areas of improvement and communicate them to the learner.

Note: This table is an overview of research done by Lidz, C. S. (1991). Practitioner's Guide to Dynamic Assessment. New York: Guilford Press.

\section{Peer-revision and feedback in writing projects}

A number of studies have suggested that simply correcting errors in second language learners' writing has no effect on the development of their writing skills; however, when this error correction is coupled with feedback provided by an expert, students come to a better understanding of the error and are able to correct it in subsequent writings (Byrd, 2003; Kepner, 1991; Lalande, 1982; Paton, 2002; Reichelt, 1999, 2001; Semke, 1982, 1984; Yang, 2006; but see Ferris, 1999; and Truscott, 1996, 1999 for information on error correction) and also on subsequent revisions of the same writing piece (Chaudron, 1984; Connor \& Asenavage, 1994; Hedgcock \& Lefkowitz, 1992; Mendonça \& Johnson, 1994; Nelson \& Murphy, 1993; Villamil \& de Guerrero, 1996, 1998). Such peer- and instructor-feedback may form part of a variety of teaching methodologies including writing portfolio projects (Padilla, Aninao, \& Sung, 1996; Paesani, 2006; Rowinsky-Geurts, 2010; Shlayer, 2000; Williams, 2005; Woody, 2005) and writing workshop projects (Barnard, 2002; Kelly, 2009; Porcaro \& Gudeman Johnson, 2003; Ransdell, 2001; Walvoord, 1986). Given the results from these studies, it is very likely that an excellent way to implement feedback in the classroom is through collaborative debriefing sessions.

In Barnard's (2002) study, a whole-class workshop methodology is presented in which students are trained to be expert peer editors by learning about the difficulties and benefits of providing feedback and assessing a peer's writing. As such, Barnard argues that this develops the skills and self-confidence necessary to assess their own writing while also improving the writing of others. Barnard's study revealed significant development in the students' writing due to the workshop design and peer feedback and suggested that these types of workshops "dramatically impact student writing, students' conception of themselves as writers, and instructors' understanding of their identifications as teachers of writing" (p. 124). Furthermore, peer-editors who provide valuable feedback become familiar with a variety of writing techniques, qualities, and acquire skills in critical analysis that help shape their own writing skills (Paton, 2002; Tang \& Tithecott, 1999). Similar benefits for employing writing workshops also have been revealed in children (Lillios \& Iding, 1996; Porcaro \& Gudeman Johnson, 2003).

An important benefit that peer-editing and writing workshop projects bring to the second language classroom is their collaborative nature, a product of the peer- and instructor-interaction and debriefing sessions. A number of studies have suggested that collaborative work facilitates writing development more so than lecturebased, prescriptive pedagogies (de Guerrero \& Villamil, 1994; Lockhart \& Ng, 1995; Mangelsdorf \& Schlumberger, 1992; McGroarty \& Zhu, 1997; Nelson \& Murphy, 1993). Furthermore, when students are assessed not only on their own writing, but also on the quality of feedback and interaction they provide to their peers, a state of commitment and interest is fostered which creates a richer learning environment (de Guerrero \& Villamil, 1994). Regarding the feedback debriefing sessions, the collaborative nature of this interaction is based on a variety of student characteristics such as peer-advising, clarification, and reliance on the first language to maintain control of the revision process (Villamil \& de Guerrero, 1996). Such behaviors form part of scaffolding writing techniques within the ZPD in which writing development is guided by "a long-term sense of direction and continuity, a local plan of action, and a moment-to-moment interactional decision-making" (van Lier, 1996, p. 199). At some point during this 
collaboration, the expert and novice come to a mutual agreement with respect to the feedback provided to improve writing and the revisions in question (i.e., two minds become one, so to speak) (Adair-Hauck \& Donato, 1994).

An additional advantage to writing workshops is that they create the possibility for students to write for authentic audiences. Previous researchers have shown that when students write for those other than the instructor, they feel as though their writing really matters (Atwell, 1998; Black, personal communication, October 9, 2008, 2009; Calkins, 1994; Dahl \& Farnan, 1998; Graves, 1994; Kelley, 2009) which leads them to "use their vision of an intended audience to make decisions that shape a piece of writing" (Dahl \& Farnan, p. 51). Furthermore, when students are aware that their writing will be eventually appreciated by an authentic audience, they take more pleasure in the writing process and begin to see it as means of communication to reach out to others and not simply as an academic responsibility that later will be limited to the assessment of the instructor (Elbow, 2002; Kelly, 2009). A valid example comes from pedagogical considerations employed by university instructors Kelley (2009) and Black (2009) in which second language learners enrolled in their writing courses compose children's books in the form of short stories that are later presented to grade school students in the community. These researchers have found significant improvement in their students' writing and the dedication that they put into their creative writing pieces. Kelly furthermore argues that this type of project provides an outlet for the instructor to introduce his/her students to an innovative methodology which the students may apply to their own teaching in the future should they decide to become future educators.

As discussed above, both authentic writing workshops and scaffolding writing techniques within learners' ZPDs have fostered second language writing development. However, to the researcher's knowledge, there has been no study to date that has combined these two elements in the context of creating a professional magazine intended for an authentic audience. As such, the purpose of the present study is to combine the practice of an authentic writing workshop with scaffolding writing techniques within second language learners' ZPDs. The upcoming sections present the current study and the results from the statistical procedures employed. Based on these results, a discussion is provided and implications for future studies and the second language classroom are outlined.

\section{PRESENT STUDY}

The objective of the present study is to examine the development of second language writing through scaffolding writing techniques within a semester-long workshop-style writing course in which students created a professional magazine for an authentic audience. The methodology employed within the project is based on the theoretical contributions of the ZPD and scaffolding writing and the pedagogical considerations from Black (personal communication, October 8, 2008). It is hypothesized that scaffolding writing techniques through peerediting and feedback debriefing sessions guided by Lidz's (1991) components of assisted learning will significantly improve writing.

\section{Participants}

Twenty-two participants in the present study took part in the course project that is described below. These participants authored essays and also acted as peer-editors in groups. Each participant had a distinctive role (e.g., textual editor, stylistic editor, associate editor, editor-in-chief, etc.) in the creation of their group's magazine. At the beginning of the project, the researcher, who was also the course instructor, individually met with each of the participants to discuss with them the theory of the ZPD and scaffolding. This was an important element in the present study as it provided an opportunity to describe to the students the scaffolding criteria put forth by Lidz (1991) and the rubrics that were used to rate the essays written by their peers. In addition, the instructor provided tips on how to successfully peer-edit while emphasizing the individual role of the student. For instance, if the student acted as a stylistic editor, specific details were provided so that emphasis could be placed on stylistic elements of the essay. This is an important consideration given that a number of researchers have argued that peereditors practicing scaffolding writing techniques must understand the revision/editorial process, including how to provide constructive feedback (Byrd, 2003; Ferris, 2003; Hedgecock \& Lefkowitz, 1992; Paesani, 2006; Rothschild \& Klingenberg, 1990; Scott, 1996; Stanley, 1992). Indeed, Barnard (2002) argues that it is impossible for teachers to expect their students to perform at an effective level unless they are given training, modeling, and discussion on how to be the expert. 


\section{The authentic magazine project}

The present study puts forth a similar methodology as Barnard's (2002) writing workshop project. However, extensions are made in that students are requested to write for an authentic audience and participate in scaffolding writing techniques and feedback debriefing sessions. The participants described above were placed in two groups of seven and one group of eight. Within each group, the students nominated one another for the following positions in the creation of their magazine: two or three textual editors, two stylistic editors, one visual editor, one associate editor, and one editor-in-chief. Once the nominations occurred, the instructor individually met with each of the students to approve of their position and to ensure that they understood the role they would play in the project. As mentioned above, this also served as a training session following work done by Lidz (1991).

On different dates during the semester, each student submitted a distinct essay representing the following stylistic writings: descriptive, narrative, expository, and persuasive. Figure 2 represents the editorial cycle for the essays authored by the students in the present study. As can be seen in the figure, each essay was first peer-edited by a textual editor in their group, mainly for the purpose of improving grammar and clarity of the essay. Following this, the essays were returned to the authors and a feedback debriefing session was employed so that the authors and editors could comment on making improvements to the essay. The authors made the revisions and submitted their corrected essays to a stylistic editor in their group, who ensured that the textual revisions had been made and that the style of the essay accurately represented the type of essay in question. Once the stylistic editors provided their feedback and returned the essays to the authors, another feedback debriefing session occurred between the stylistic editors and the authors. The authors once again made the revisions and subsequently submitted the revised essays to both the associate editor and editor-in-chief. These editors reviewed the essays for fine-tuning, provided their recommendations, and facilitated a feedback debriefing session with the authors. The associate editor and editor-inchief were also responsible for ensuring that the essays were in their final format and ready to be edited by the course instructor. The authors made revisions again and submitted the corrected essays to the instructor who made the final revisions to the essays and provided a one-on-one feedback debriefing session with the authors.

This four-stage editorial process represented in Figure 2 allows students to improve their essays in a procedural, linear manner in which editorial scaffolding techniques seek to improve the: 1) language/grammar; 2) style; and 3) fine-tuning of each essay. It is also important to mention that the debriefing session stage is where the learning is expected to occur (represented in dark gray) and the reflect, revision, and resubmit stage (as shown in light gray) is where it is expected that students internalize and apply what was learned in the debriefing session.

In all, each of the four essays went through four editorial and revision stages in which a student editor or the instructor provided written feedback and oral debriefing with the student authors. Additionally, for each stage, the student editor provided a rating based on a thirty-point, instructor-created rubric (see Table 2). To ensure interrater reliability, an additional rating was assigned by the instructor at each stage using the same rubric.

Table 3 shows an example of this rating process for one of the essays rated in the present study. As can be seen in the table, two ratings are assigned at each of the four stages for inter-rater reliability. The means of the two ratings at each stage are calculated and shown on the right. In the case stage 4 , which was rated by the instructor, an additional instructor volunteered to provide a second rating. Like the example in Table 3 shows, it was expected that significant growth would be observed within each essay (i.e., incrementally growing from 18 to 27.5). In addition to this development, the researcher hypothesized that significant improvement would occur between essays (at four different points during the semester).

Once the magazine was completed, it was prepared in "sellable format" and submitted for professional printing. The final version was made available to the faculty and student body in the researcher's department. These readers served as the authentic audience that was described in the above sections. Subsequent to the distribution of the magazines, a "meet the authors and production team" open house was set up so that interested students and faculty members could discuss the magazine and the "published" essays with the students. 


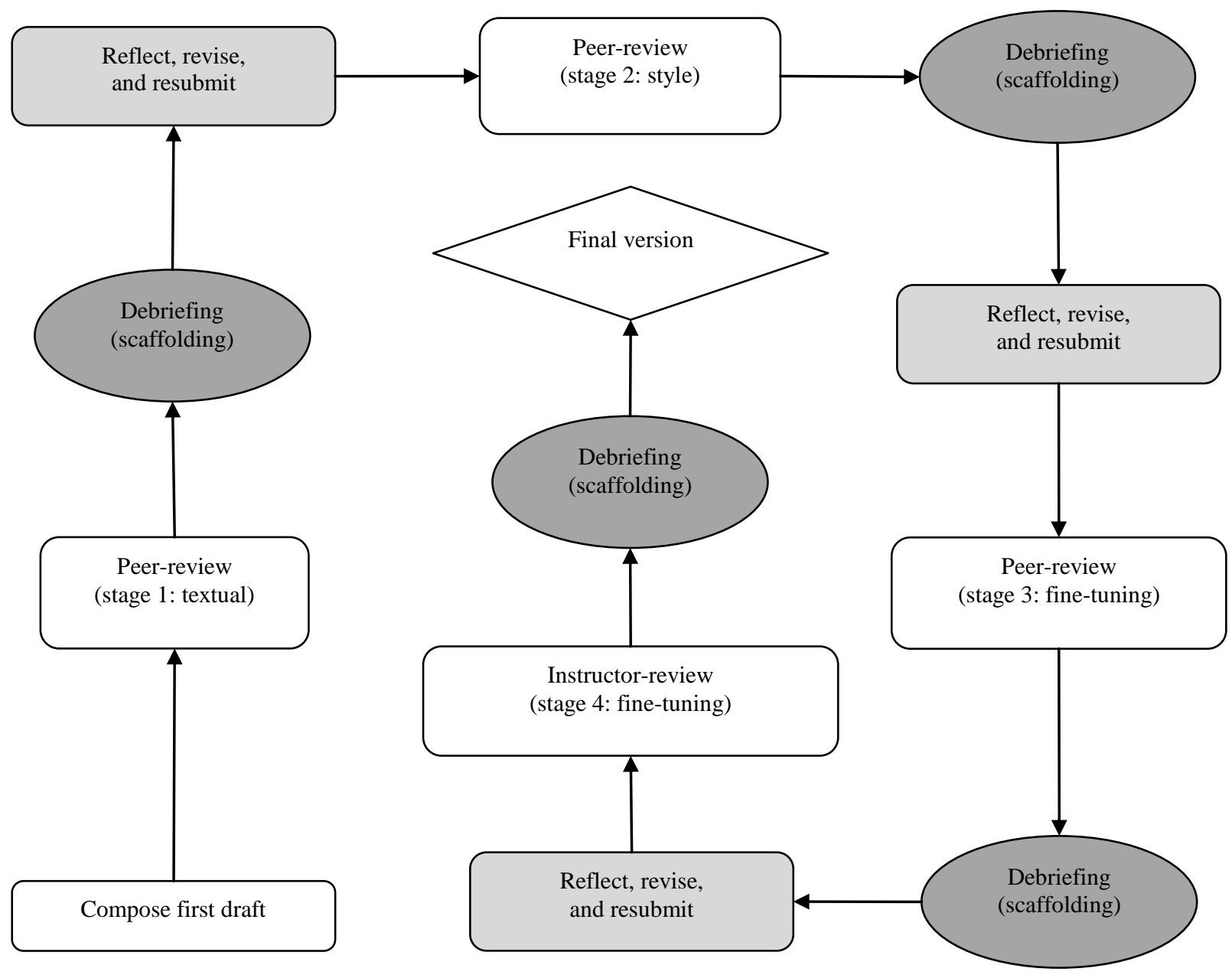

Figure 2. Editorial stages of scaffolding writing for each essay.

Table 2

Sample rubric used for evaluating essays

Please rate each using the following scale: $1=$ do not agree; $2=$ neutral; $3=$ agree.

1. The author's goals and objectives are clear.

2. The impression given to the reader is positive.

3. The details provided contribute to the objectives.

4. The given information can be directly related to the overall goal.

5. There is always sufficient description, explanation, details, and examples.

6. The author avoids using general and abstract terms that fails to capture the essence of what is needed to be described (especially with adjectives).

7. The author uses clear, precise, and eloquent vocabulary.

8. The author includes details that help involve other senses apart from visual (e.g., sense of smell, touch, etc.)

9. The vocabulary is connotative that provokes the reader's emotions.

10. The conclusion truly concludes and reiterates everything that should have been captured and imagined in the essay.

Table 3

Example of ratings from editorial stages for one essay

\begin{tabular}{lcccc}
\hline & Editor & Instructor 1 & Instructor 2 & $\frac{\text { Mean }}{18.0}$ \\
Stage 1: Textual & 18 & 18 & - & 20.5 \\
Stage 2: Stylistic & 21 & 20 & - & 24.0 \\
Stage 3: Perfection & 25 & 23 & - & 28 \\
Stage 4: Perfection & - & 27 & & 22.5 \\
\hline Mean & & & & 22.6 \\
\hline
\end{tabular}




\section{RESULTS}

The reader will recall that each essay was evaluated by two raters at four editorial stages. To ensure interrater reliability, paired-samples $t$-tests (two-tailed) were conducted between the two ratings elicited in each stage. From these tests, there were no significant differences between their ratings in any instance $(p>.05)$. The means of the two ratings assigned at each of the four stages of revisions were calculated and analyzed to measure the extent of writing development within each of the four essays (refer back to Table 3 for an example). Subsequently, mean ratings for all four essays were calculated and analyzed to measure the extent of writing development between essays. Below, separate repeated measures ANOVAs are presented using: 1) participant means as random factors with ratings (rating 1, rating 2, rating 3, rating 4) as within-group factors for each of the four essays; and 2) participant means as random factors with essays (essay 1, essay 2, essay 3, essay 4) as within-group factors. Following these results, discussion and conclusions are presented and suggestions for future research are put forth.

\section{Development within essays}

Separate repeated measures ANOVAs were conducted for each of the four essays to analyze writing development within each essay. Table 4 displays the participants' mean ratings and standard deviations (SDs)in the four editorial stages for the essays. The table also shows the overall mean for each essay in the bottom row and the overall mean for each stage in the right-most column.

Table 4

Mean stage and essay ratings (and SDs in parentheses)

\begin{tabular}{lccccc}
\hline & Essay 1 & $\underline{\text { Essay } 2}$ & $\underline{\text { Essay } 3}$ & $\underline{\text { Essay 4 }}$ & $\underline{\text { Stage Mean }}$ \\
Stage 1: Textual & $18.35(2.25)$ & $20.09(2.98)$ & $21.28(3.07)$ & $22.11(1.64)$ & $20.46(2.49)$ \\
Stage 2: Style & $20.33(1.61)$ & $21.57(2.90)$ & $23.65(3.02)$ & $24.80(1.37)$ & $22.59(2.23)$ \\
Stage 3: Perfection & $20.59(1.66)$ & $24.30(1.99)$ & $23.54(2.21)$ & $26.46(1.37)$ & $23.72(1.81)$ \\
Stage 4: Perfection & $26.46(2.17)$ & $26.00(1.71)$ & $28.72(.95)$ & $28.70(1.09)$ & $27.47(1.48)$ \\
\hline Essay Mean & $21.43(1.47)$ & $22.99(2.07)$ & $24.30(1.91)$ & $25.52(.96)$ & \\
\hline
\end{tabular}

What may be immediately apparent is that participants' essays were rated higher with each stage. Indeed, results from the ANOVAs confirmed significant improvement between stages for all four essays. For Essay 1, $F(3$, $20)=61.23, p<.001$, paired-samples $t$-tests (two-tailed) revealed significant improvement between stage 1 and stage $2, t(22)=6.04, p<.001$, and stage 3 and stage $4, t(22)=11.36, p<.001$. There was no significant difference between stage 2 and stage $3(p>.05)$. For Essay 2, $F(3,20)=32.38, p<.001$, paired-samples $t$-tests (two-tailed) revealed significant improvement between all stages: stage 1 and stage $2, t(22)=4.25, p<.001$, stage 2 and stage 3 , $t(22)=6.89, p<.001$, and stage 3 and stage $4, t(22)=4.75, p<.001$. For Essay $3, F(3,20)=65.50, p<.001$, paired-samples $t$-tests (two-tailed) revealed significant improvement between stage 1 and stage $2, t(22)=4.25, p<$ .001 , and stage 3 and stage $4, t(22)=12.39, p<.001$. There was again no significant difference between stage 2 and stage $3(p>.05)$. Finally, for Essay $4, F(3,20)=86.38, p<.001$, paired-samples $t$-tests (two-tailed) revealed significant improvement between all stages: stage 1 and stage $2, t(22)=8.38, p<.001$, stage 2 and stage $3, t(22)=$ $5.14, p<.001$, and stage 3 and stage $4, t(22)=7.51, p<.001$. The results from these statistical analyses support the notion that scaffolding writing techniques led to significant improvement for subsequent versions of an essay (see Figure 3).

These results imply that there was steady, continuous improvement of writing skills in the context of the pedagogical considerations highlighted (i.e., ZPD, scaffolding writing, authentic audience). The next analyses will explore whether or not writing development for future essays (i.e., at future times during the semester) will also be observed as was the case within essays. 


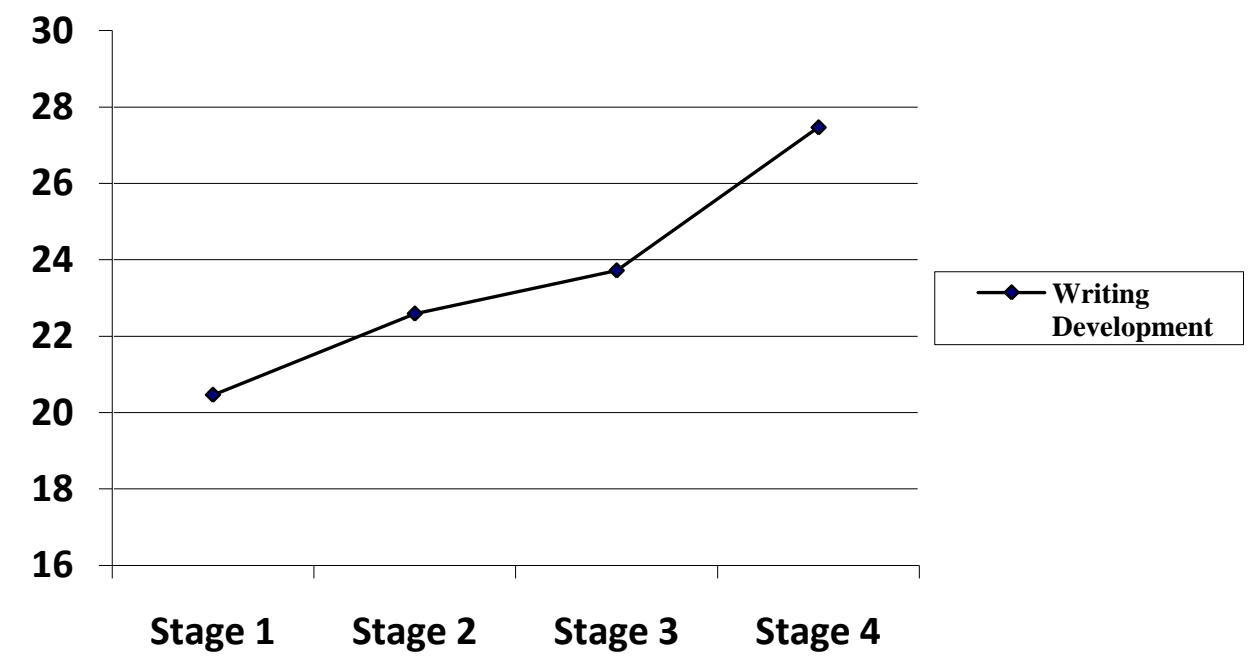

Figure 3. Writing development within essays.

\section{Development between essays}

An additional repeated measures ANOVA was conducted to analyze writing development between the four essays. Referring back to Table 4, the mean ratings for each of the four essays are displayed at the bottom of the table. The reader's attention will be drawn to an apparent increase in mean ratings from left to right. Not surprisingly, the results from the ANOVA confirmed significant improvement between the four essays, $F(3,20)=$ 42.54, $p<.001$. Paired-samples $t$-tests (two-tailed) revealed significant differences between Essay 1 and Essay 2, $t(22)=3.13, p<.001$, Essay 2 and Essay 3, $t(22)=3.49, p<.001$, and Essay 3 and Essay 4, $t(22)=3.26, p<.001$. As in the analyses presented above, these results suggest that there was significant writing development with time (see Figure 4).

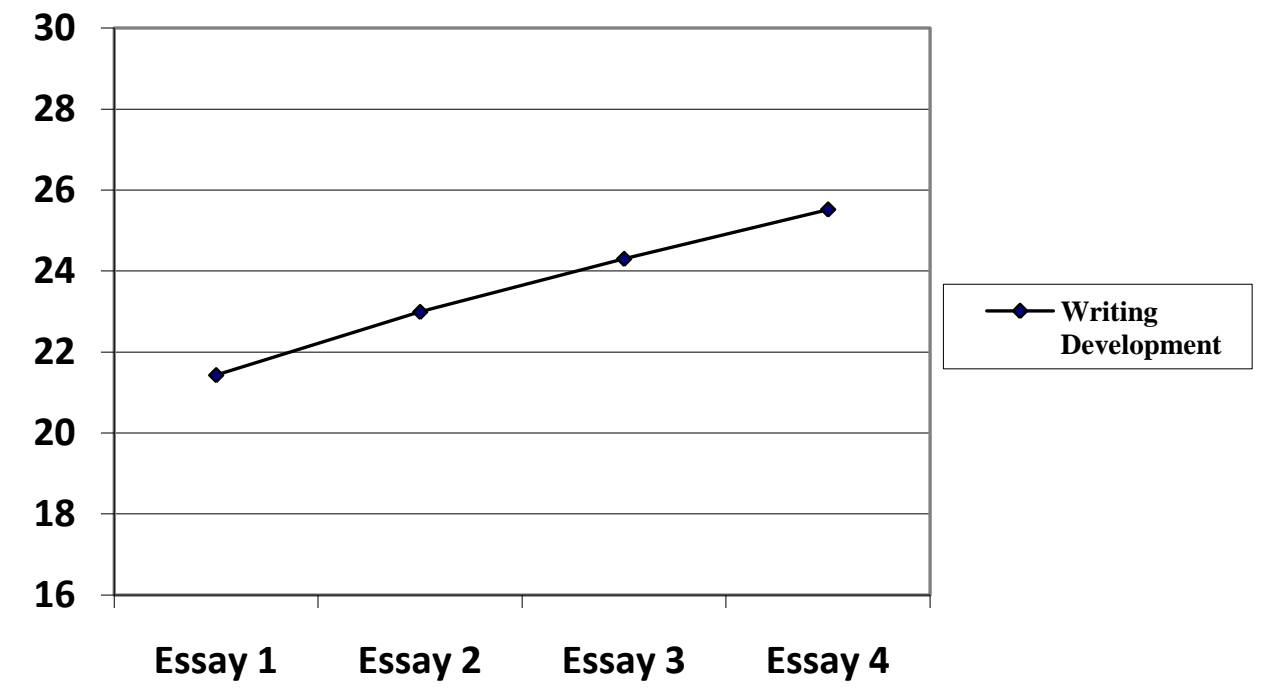

Figure 4. Writing development between essays. 
These results imply that there was again linear writing development, this time over time. Through the use of the pedagogical considerations mentioned in the present study, writing development not only occurred within essays (multiple versions of the same essay) but also between the four essays written throughout the semester.

\section{Discussion}

Overall, the results of the ANOVAs presented above demonstrate significant improvement within and between four essays. Indeed, in the first analyses, for all four essays, significant differences were observed between nearly each of the four editorial stages as was demonstrated in Figure 3. This suggests that scaffolding writing techniques within the learners' ZPDs facilitate the development of writing skills in the second language and provides evidence for the notion that feedback can help writing improve with additional revisions of the same essay (see also Chaudron, 1984; Connor \& Asenavage, 1994; Hedgcock \& Lefkowitz, 1992; Mendonça \& Johnson, 1994; Nelson \& Murphy, 1993; Villamil \& de Guerrero, 1996, 1998). Additional analyses were conducted to test whether or not the same could be said with subsequent, distinct essays (written at four evenly-distributed points of time during the semester). These findings also confirmed a significant linear development of writing improvement between each of the four essays as was demonstrated in Figure 4. This suggests that language learners are able to utilize and apply what they have learned in one essay to subsequent, non-related essays. In terms of the ZPD, this finding provides evidence for the theoretical claims represented in Figure 1 in that one ZPD's level of assisted learning is the next ZPD's level of unassisted learning. This is an important finding as it provides evidence that in the context of a writing workshop project involving the production of a professional magazine for an authentic audience, scaffolding writing techniques including feedback debriefing sessions within learners' ZPDs facilitate the development of second language writing skills.

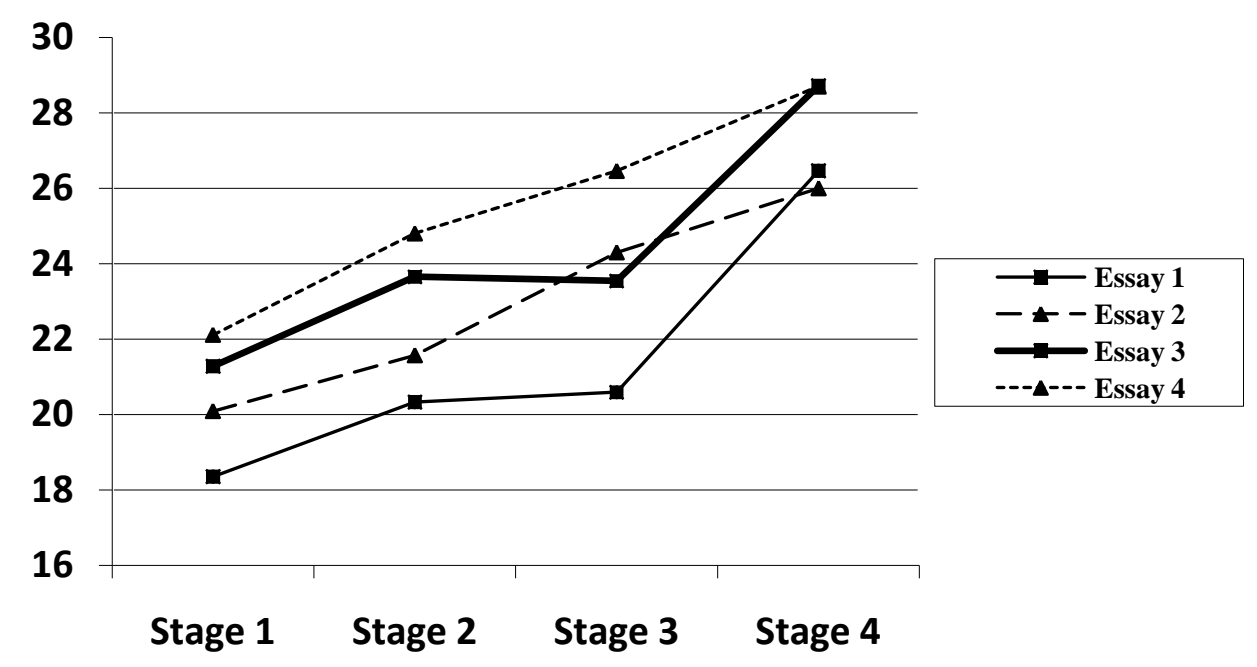

Figure 5. Differential learning effects observed in essays.

Another observation that merits discussion is a plateau effect in writing development that was observed in both Essay 1 and Essay 3. As reported in the results above, there was no reported for significant improvement between stage 2 and stage 3 in the cases of Essay 1 and Essay 3. Although in the context of all four essays, this did not impede an overall significant development between stage $2(M=22.59)$ and stage $3(M=23.72), t(22)=6.62, p$ $<.001$, Essay 1 and Essay 3 provide an example in which writing development in the present study did not proceed in a consistent manner. On the contrary, in these two cases, as can be seen in solid lines in Figure 5, there is a marked plateau effect for Essay 1 and Essay 3 in which writing development temporarily ceases to increase between stages 2 and 3. The cases of Essays 2 and 4 shown in dotted-lines, however, paint a different picture in which learning did not plateau. This is an important factor to consider and deserves attention in future studies. Indeed, if writing development, or at least in the context of the instructional treatment in the present study, involves a (brief) 
period in which development is temporarily discontinued, then perhaps pedagogical considerations could be explored to help minimize this pause in development. Nonetheless, it may very well be that this phenomenon of a plateau period is a normal process in language learning. Previous researchers have gone so far as to argue that in learning development, large improvements come very quickly, followed by a rate of improvement that plummets to nearly nothing (Rowntree, 1981; Xu, 2009).

The results discussed in the present study should not be surprising given the theoretical claims of the ZPD and scaffolding writing and when considering the learning benefits associated with a magazine workshop project designed for an authentic audience. This project provided a learning environment which facilitated scaffolding writing through feedback debriefing sessions. This collaboration included a discussion of the revisions between an expert and novice learner with the goal of improving writing within the novice's ZPD. The course project presented in the present study also provided an outlet to quantify the theoretical hypotheses that were presented in Figure 1. The theoretical implications of the present findings support the notion that the writing skills acquired from expert assistance in editorial stage 1 (ZPD1) became the foundation for what could be done without assistance in editorial stage 2 (ZPD2); skills acquired in editorial stage 2 became a basis for what could be done without assistance in editorial stage 3, and so on. In all, the results from the present study suggest that in the context of the pedagogical considerations employed, with each revision of any given essay, writing improved. Furthermore, the results imply that these techniques additionally led to writing development over time.

\section{CONCLUSION}

In the present study, the theoretical framework of the ZPD (Vygotsky, 1978, 1986) and scaffolding writing (Bodrova \& Leong, 1995, 1996) formed the foundation to explore writing development in a second language. To test this theoretical framework, a writing workshop project in which language learners work in groups to create a professional magazine designed for an authentic audience was discussed. In the project, the participants wrote four essays, each of which going through four editorial stages of scaffolding writing (i.e., textual reconstruction following Wood et al. (1976) and feedback debriefing sessions following Lidz, 1991). It was the purpose of the present study to investigate whether or not these pedagogical techniques would contribute to significant development within the four essays and, moreover, between the four essays written on four occasions during an academic semester. The results from the statistical analyses revealed significant improvement within and between all four essays demonstrating continuous writing development not only with subsequent versions of the same essay, but also with essays written at different points of the semester. An interesting finding was also discussed that revealed a plateau effect in writing development in the present study. In fact, for two of the four essays, there was a leveling-off period in which development did not show a significant increase between stages 2 and 3. Although plateau effects have been revealed in other studies, future research may wish to seek ways in which this plateau can be avoided in order to continue a linear (and potentially, more efficient) process of learning. These studies, however, may have to first address whether or not such a specialized instructional practice would disrupt what may be a nature process in writing development.

In all, the results from the present study support a notion that scaffolding writing techniques within the ZPD facilitate the development of second language writing skills. This study has also shown that by framing these techniques within a writing workshop project such as the magazine project for an authentic audience, the language instructor is positioned to contextualize the optimal learning environment for writing development. Future studies are needed to continue exploring how writing development is facilitated and the best possible pedagogical considerations that help lead to such development. Additionally, attention should be given to investigate the extent to which this innovative teaching methodology contributes to the development of other skills in language learning (oral, social, practical, etc.).

\section{AUTHOR INFORMATION}

Dr. John W. Schwieter is assistant professor of Spanish and linguistics at Wilfrid Laurier University in Waterloo, Ontario, Canada. He has published a book and several articles and book chapters in the areas of psycholinguistics, second language acquisition, and socio-cultural linguistics. At Wilfrid Laurier University, he instructs courses in Spanish and linguistics at all levels. 


\section{REFERENCES}

1. Adair-Hauck, B., \& Donato, R. (1994). Foreign language explanations within the zone of proximal development. Canadian Modern Language Review, 50, 532-557.

2. Aljaafreh, A., \& Lantoff, J. P. (1994). Negative feedback as regulation and second language learning in the zone of proximal development. The Modern Language Journal, 78, 465-487.

3. Antón, M., \& DiCamilla, F. (1998). Socio-cognitive functions of L1 collaborative interaction in the L2 classroom. Canadian Modern Language Review, 54, 314-342.

4. Atwell, N. (1998). In the middle: New understandings about writing, reading, and learning. Portsmouth, NH: Heinemann.

5. Balaban, N. (1995). Seeing the child, knowing the person. In W. Ayers (Ed.), To become a teacher (pp. 4957). New York: Teachers College Press.

6. Barnard, I. (2002). Whole-class workshops: The transformation of students into writers. Issues of Writing, 12(2), 124-143.

7. Bell, P., \& Davis, E. (1996, April). Designing an activity in the knowledge integration environment. Paper presented at the American Educational Research Association, New York, NY.

8. Berk, L., \& Winsler, A. (1995). Scaffolding children's learning. Vygotsky and early childhood education. Washington, DC: National Association for the Education of Young Children.

9. Black, C. (2009). Engaging Students: Best Practices in Active Learning. Madison, WI: Atwood Publishing.

10. Bodrova, E., \& Leong, D. (1995). Scaffolding the writing process: The Vygotskian approach. Colorado Reading Council Journal, 6, 27-29.

11. Bodrova, E., \& Leong, D. (1996). Tools of the mind: The Vygotskian approach to early childhood education. Englewood Cliffs, NJ: Merrill/Prentice Hall.

12. Borthick, A., Jones, D., \& Wakai, S. (2003). Designing learning experiences within learners 'Zones of Proximal Development' (ZPDs): Enabling collaborative learning on-site and online. Journal of Information Systems, 17(1), 107-134.

13. Brown, A., \& Reeve, R. (1987). Bandwidths of confidence: The role of supportive contexts in learning and development. In L. Liben (Ed.), Development and learning: Conflict or congruence (pp. 173-223).

Hillsdale, NJ: Lawrence Erlbaum.

14. Bruner, J. (1978). The role of dialogue in language acquisition. In S. Jarvella \& W. Levelt (Eds.), The child's conception of language (pp. 214-256). New York: Max Plank Institut for Psycholinguistik.

15. Byrd, D. (2003). Practical tips for implementing peer editing tasks in the foreign language classroom. Foreign Language Annals, 36(3), 434-441.

16. Calkins, L. (1994). The art of teaching writing. Portsmouth, NH: Heinemann.

17. Cazden, C. (1983). Adult assistance to language development: Scaffolds, models, and direct instruction. In R. Parker \& F. Davis (Eds.), Developing literacy: Young children's use of language (pp. 3-18). Newark, DE: International Reading Association.

18. Chaudron, C. (1984). The effects of feedback on students' composition revisions. RELC Journal, 15, 1-16.

19. Connor, U., \& Asenavage, K. (1994). Peer response groups in ESL writing classes: How much impact on revision? Journal of Second Language Writing, 3, 257-276.

20. Dahl, K., \& Farnan, N. (1998, February). Children's writing: Perspectives from research. Paper presented at The National Reading Conference of the International Reading Association, Chicago, IL.

21. Daniels, H. (1994). Literature Circles: Voice and choice in the student-centered classroom. Markham: Pembroke Publishers

22. Daniels, H. (2001) Vygotsky and pedagogy. New York: Routledge/Falmer.

23. DiCamilla, F., \& Antón, M. (1997). Repetition in the collaborative discourse of L2 learners: A Vygotskian perspective. Canadian Modern Language Review, 53, 609-633.

24. Donato, R. (1994).Collective scaffolding in second language learning. In J. Lantolf \& G. Appel (Eds.), Vygotskian approaches to second language research (pp. 33-56). Norwood, NJ: Ablex.

25. Elbow, P. (2002). The role of publication in the democratization of writing. In C. Weber (Ed.), Publishing with students: A comprehensive guide (pp. 1-8). Portsmouth, NH: Heinemann.

26. Ferris, D. (1999). The case for grammar correction in the L2 writing classes: A response to Truscott (1996). Journal of Second Language Writing, 8, 1-11. 
27. Ferris, D. (2003). Response to student writing: Implications for second language students. Mahway, NJ: Lawrence Erlbaum.

28. Graves, D. (1994). A fresh look at writing. Portsmouth, NH: Heinemann.

29. Guerrero, M. de, \& Villamil, O. (1994). Social-cognitive dimensions of interaction in L2 peer revision. The Modern Language Journal, 78, 484-496.

30. Guerrero, M. de, \& Villamil, O. (2000). Activating the ZPD: Mutual scaffolding in L2 peer revision. The Modern Language Journal, 84(1), 51-68.

31. Hedgcock, J., \& Lefkowitz, N. (1992). Collaborative oral/aural revision in foreign language writing instruction. Journal of Second Language Writing, 1, 255-276.

32. Holton, D., \& Clarke, D. (2006). Scaffolding and metacognition. International Journal of Mathematical Education in Science and Technology, 37(2), 127-143.

33. Kelly, K. (2009). Practice what you preach: A teacher educator is reminded of important lessons. The Clearing House: A Journal of Educational Strategies, Issues, and Ideas, 82(3), 145-151.

34. Kepner, C. (1991). An experiment in the relationship of types of written feedback to the development of second-language writing skills. The Modern Language Journal, 75, 305-313.

35. Lalande, J. (1982). Reducing composition errors: An experiment. The Modern Language Journal, 66, 140149.

36. Lantoff, J., \& Aljaafreh, A. (1995). L2 learning in the zone of proximal development: A revolutionary experience. International Journal of Educational Research, 23(7), 51-64.

37. Lidz, C. (1991). Practitioner's guide to dynamic assessment. New York: Guilford Press.

38. Lillios, M., \& Iding, M. (1996). How ninth graders respond to teacher and peer comments on their writing. Teaching and Change, 3(3), 211-226.

39. Lockhart, C., \& Ng, P. (1995). Analyzing talk in ESL peer response groups: Stances, functions, and contents. Language Learning, 45, 605-655.

40. Mangelsdorf, K., \& Schlumberger, A. (1992). ESL student response stances in a peer-review task. Journal of Second Language Writing, 1, 235-254.

41. McGroarty, M., \& Zhu, W. (1997). Triangulation in classroom research: A study of peer revision. Language Learning, 47, 1-43.

42. Mendonça, C., \& Johnson, K. (1994). Peer review negotiations: Revision activities in ESL writing instruction. TESOL Quarterly, 28, 745-769.

43. Moll, L. (1990). Vygotsky and education: Instructional implications and applications of sociohistorical psychology. Cambridge, MA: Cambridge University Press.

44. Moll, L., \& Whitmore, K. (1993). Vygotsky in classroom practice: Moving from individual transition to social interaction. In E. Forman, N. Minick, \& C. Stone (Eds.), Contexts for learning: Sociocultural dynamics in children's development (pp. 19-42). New York: Oxford University Press.

45. Nelson, G., \& Murphy, J. (1993). Peer response groups: Do L2 writers use peer comments in revising their drafts? TESOL Quarterly, 27, 135-141.

46. Newman, D., Griffin, P., \& Cole, M. (1989). The construction zone: Working for cognitive change in school. Cambridge: Cambridge University Press.

47. Ohta, A. (1995). Applying sociocultural theory to an analysis of learner discourse: Learner-learner collaborative interaction in the zone of proximal development. Issues in Applied Linguistics, 6(2), 93-121.

48. Padilla, A., Aninao, J., \& Sung, H. (1996). Development and implementation of student portfolios in foreign language programs. Foreign Language Annals, 29(3), 429-438.

49. Paesani, K. (2006). Exercices de style: Developing multiple competencies through a writing portfolio. Foreign Language Annals, 39(4), 618-639.

50. Paton, F. (2002). Approaches to productive peer review. In D. Roen, Pantoja, V., Yena, L., Miller, S., \& Waggoner, E., (Eds.), Strategies for teaching first-year composition (pp. 290-300). Urbana: NCTE.

51. Porcaro , J., \& Gudeman Johnson, K. (2003). Building a whole-language writing program. Kappa Delta Pi Record, Winter, 74-79.

52. Ransdell, M. (2001). Local fourth and fifth grade teachers' conceptions and practices of cooperative learning in science. Unpublished Dissertation, University of Kentucky, Lexington, KY.

53. Reichelt, M. (1999). Toward a more comprehensive view of L2 writing: Foreign language writing in the Journal of Second Language Writing, 8, 181-204. 
54. Reichelt, M. (2001). A critical review of foreign language writing research on pedagogical approaches. The Modern Language Journal, 85(4), 578-598.

55. Rogoff, B., \& Wertsch, J. (1984). Children's learning in the zone of proximal development: New Directions for Child Development. San Francisco: Jossey-Bass.

56. Rommetveit, R. (1985). Language acquisition as increasing linguistic structuring of experience and symbolic behavior control. In J. Wertsch (Ed.), Culture, communication and cognition: Vygotskyan perspectives (pp. 183-204). Cambridge: Cambridge University Press.

57. Rothschild, D., \& Klingenberg, F. (1990). Self and peer evaluation of writing in the interactive ESL classroom: An exploratory study. TESL Canada Journal, 8, 52-65.

58. Rowinsky-Geurts, M. (2010). When learning matters: Students assessment using portfolios in higher education. In C. Black (Ed.), The Dynamic Classroom: Engaging Students in Higher Education. Madison, WI: Atwood Publishing.

59. Rowntree, D. (1981). Developing courses for students. London: McGraw Hill.

60. Santoso, A. (2008). The art of scaffolding an EFL writing class in a hybrid environment: A practical experience. International Journal of the Computer, the Internet and Management, 16(3), 8.1-8.12.

61. Saye, J., \& Brush, T. (2002). Scaffolding critical reasoning about history and social issues in multimediasupported learning environments. Educational Technology Research \& Development, 50(3), 77-96.

62. Scott, V. (1996). Rethinking foreign language writing. Boston: Heinle \& Heinle.

63. Semke, H. (1982, November). Correcting students' freewriting-Help or hindrance? Paper presented at the American Council on the Teaching of Foreign Languages, New York, NY.

64. Semke, H. (1984). Effects of the red pen. Foreign Language Annals, 17, 195-202.

65. Silva, T., \& Brice, C. (2004). Research in teaching writing. Annual Review of Applied Linguistics, 24, 70106.

66. Simons, K., \& Klein, J. (2007). The impact of scaffolding and student achievement levels in a problembased learning environment. Instructional Science, 35, 41-72.

67. Stanley, J. (1992). Coaching student writers to be more effective peer evaluators. Journal of Second Language Writing, 1, 217-233.

68. Stone, C. (1993). What's missing in the metaphor of scaffolding? In E. Forman, N. Minick, \& C. Stone (Eds.), Contexts of learning: Sociocultural dynamics of children's development (pp. 169-183). New York: Oxford University Press.

69. Stone, C. (1998). The metaphor of scaffolding: Its utility for the field of learning disabilities. Journal of Learning Disabilities, 31, 344-364.

70. Stone, C. (2004, March). The role of language in adults' scaffolding of children's learning. Paper presented at The Katherine G. Butler Symposium on Child Language: Innovations in Research and Practice. Clearwater Beach, FL.

71. Stone, C., \& Wertsch, J. (1984). A social interactional analysis of learning disabilities remediation. Journal of Learning Disabilities, 17, 194-199.

72. Tang, G., \& Tithecott, J. (1999). Peer response in ESL writing. TESL Canada Journal, 16(2), 20-38.

73. Truscott, J. (1996). The case against grammar correction in L2 writing classes. Language Learning, 46, 327-369.

74. Truscott, J. (1999). The case for "The case against grammar correction in L2 writing classes": A response to Ferris. Journal of Second Language Writing, 8, 111-122.

75. van der Veer, R., \& Valsiner, J. (1991). Understanding Vygotsky: A quest for synthesis. Cambridge, MA: Blackwell.

76. van Lier, L. (1996). Interaction in the language curriculum: Awareness, autonomy and authenticity. New York: Longman.

77. Verenikina, I. (2003). Understanding scaffolding and the ZPD in educational research. In P. Jeffrey (Eds.), Proceedings of the Association for Active Educational Researchers/New Zealand Association for Research in Education (. Auckland: AARE.

78. Villamil, O., \& Guerrero, M. de (1996). Peer revision in the L2 classroom: Social-cognitive activities, mediating strategies, and aspects of social behavior. Journal of Second Language Writing, 5, 51-75.

79. Villamil, O., \& Guerrero, M. de (1998). Assessing the impact of peer revision on L2 writing. Applied Linguistics, 19, 491-514. 
80. Vygotsky, L. (1978). Mind in society: The development of higher psychological processes. Cambridge, MA: Harvard University Press.

81. Vygotsky, L. (1986). Thought and language (A. Kozulin, Trans.). Cambridge, MA: MIT Press.

82. Vygotsky, L. (1987). The collected works of L. S. Vygotsky. (R. W. Rieber \& A. S. Carton, Trans.). New York: Plenum Press.

83. Walvoord, B. (1986). Student response groups: Training for autonomy. The Writing Instructor, 11, 39-47.

84. Wertsch, J. (1979). From social interaction to higher psychological processes: A clarification and application of Vygotsky's theory. Human Development, 22, 1-22.

85. Wertsch, J. (1985). Vygotsky and the social formation of mind. Cambridge, MA: Harvard University Press.

86. Wertsch, J., \& Stone, C. (1985). The concept of internalization in Vygotsky's account of the genesis of higher mental functions. In J. Wertsch (Ed.), Culture, communication and cognition: Vygotskian perspectives. Cambridge: Cambridge University Press.

87. Williams, J. (2005). Teaching writing in second and foreign language classrooms. Boston: McGraw Hill.

88. Wood, D., Bruner, J., \& Ross, G. (1976). The role of tutoring in problem solving. Journal of Child Psychology and Psychiatry, 17, 89-100.

89. Wood, D., \& Middleton, D. (1975). A study of assisted problem solving. British Journal of Psychology, 66, 181-191.

90. Woody, D. (2005). Language program articulation from the perspective of the learner: Constructing coherence through the use of a language learning portfolio. In C. Barrette \& K. Paesani (Eds.), Language program articulation: Developing a theoretical foundation (pp. 131-148). Boston: Heinle \& Heinle.

91. Yang, Y. (2006). Feedback on college EFL students' compositions. US-China Foreign Language, 4(11), 93-96.

92. Yelland, N., \& Masters, J. (2007). Rethinking scaffolding in the information age. Computers and Education, 48, 362-382.

93. Xu, Q. (2009). Moving beyond the intermediate EFL learning plateau. Asian Social Science Journal, 5(2), 66-68. 
NOTES 